\title{
Synthesis, characterization, thermal and electrical properties of composite of polyaniline with cobaltmonoethanolamine complex
}

\author{
REHANA RASOOL and KOWSAR MAJID* \\ Department of Chemistry, National Institute of Technology Srinagar, Hazratbal Srinagar 190 006, India
}

MS received 21 July 2013; revised 8 October 2013

\begin{abstract}
The present paper involves the synthesis of polyaniline (PANI) composite with cobaltmonoethanolamine $\left[\mathrm{Co}(\mathrm{mea})_{2}\left(\mathrm{H}_{2} \mathrm{O}\right)_{2} \mathrm{Cl}_{2}\right]$ complex via in situ oxidative polymerization by ammonium persulphate. The complex has been synthesized by refluxing method. The composite has been subjected to UV-Visible spectra, FT-IR, X-ray diffraction, SEM and electrical conductivity characterization techniques. Thermal analysis has been done by using TG and DSC techniques. FT-IR absorption peaks confirm the insertion of complex in the backbone of PANI. SEM of the composite also supports its successful synthesis. The XRD of composite also shows crystalline structure hence, proving the successful synthesis of PANI. Thermal analysis shows enhanced thermal stability of polyaniline. In the present composite system, the polymerization of PANI with $\left[\mathrm{Co}(\mathrm{mea})_{2}\left(\mathrm{H}_{2} \mathrm{O}\right)_{2} \mathrm{Cl}_{2}\right]$ complex causes strong interfacial interactions between PANI and $\left[\mathrm{Co}\left(\mathrm{mea}_{2}\left(\mathrm{H}_{2} \mathrm{O}\right)_{2} \mathrm{Cl}_{2}\right]\right.$ complex crystallites, also suggested by the FT-IR and XRD studies, thereby changing the molecular conformation of PANI from compact coil structure to an expanded coil-like structure. As a consequence, there is an enhancement in the conductivity of composite of PANI up to certain dopant concentration. The anticorrosive property of a coating of $\mathrm{PANI} /\left[\mathrm{Co}(\mathrm{mea})_{2}\left(\mathrm{H}_{2} \mathrm{O}\right)_{2} \mathrm{Cl}_{2}\right]$ composite on mild steel coupon in $3 \mathrm{M} \mathrm{HNO}_{3}$ was evaluated using weight loss measurement and compared with pure polyaniline coating. The said composite has shown anticorrosive property and can thus, act as a potent dopant for enhancing corrosion resistance of PANI coatings.
\end{abstract}

Keywords. Polyaniline; oxidative polymerization; cobaltmonoethanolamine complex; thermal analysis; electrical conductivity.

\section{Introduction}

During past two decades, both fundamental and applied research in conducting polymers and its composites has grown enormously (Skotheim et al 1998). Among the conducting polymers, polyaniline (PANI) and its derivatives have attracted much interest because of their higher environmental, thermal and chemical stabilities along with high conductivity (Meixiang 1998). Conducting polymers and its composites have found application as transducers of biosensor (Kros et al 2001), electrodes of rechargeable batteries (Kaeami et al 2003), artificial nerves and muscles (Yamauchi et al 2005), gas sensors (Lin et al 1998), solid electrolytic capacitor, diodes, transistors (Noh et al 2003), anti-static electromagnetic shielding (Lee et al 2001; Koul et al 2001) and biomedical applications (Pfaendner 2010). In addition to this, majority of the literature focuses on the use of these materials as anti-corrosive coating on metal surfaces (Sambhu et al 2011). Since, corrosion protection of the metal is one of the most serious problems that mankind has to face. In this direction, conducting polymers and their composites have proved as good candidates for use as corrosion

*Author for correspondence (kowsarmajid@rediffmail.com) inhibitors that too with environmental friendship. It has been reported that PANI-based coatings can prevent corrosion even in scratched areas, where bare-steel surface is exposed to the aggressive environment (Zarras et al 2003). It has also been reported that three layers of coating are required with traditional materials to obtain an adequate protection of metal surfaces against corrosion, whereas a single coat of conducting polymers and their composites can provide the same degree of protection, leading to the substantial savings of material as well as cost of application. It is an established fact now that novel properties of composites can be derived from the successful combination of the characteristics of the parent constituents into a single material. Therefore, the preparation of PANI composites has been the subject of considerable interest since the development of composite materials. The composites of PANI with various metal-oxides, inorganic and organic nanoparticles have been synthesized and properties of PANI have improved significantly. Various composites of PANI with various fillers, binders and dopants have been synthesized, characterized and explored for many applications. For example, composites of PANI with dopants like $\mathrm{MoO}_{3}, \mathrm{Zro}_{2}, \mathrm{TiO}_{2}, \mathrm{WO}_{3}, \mathrm{Mn}_{3} \mathrm{O}_{4}$ and $\mathrm{MnO}_{2}$ have been synthesized, characterized, and have shown significant applications (Gurunathan et al 2003). 
Composites of PANI with $\mathrm{MoO}_{3}$ have increased thermal stability of the polymer. The conductivity of PANI- $\mathrm{MoO}_{3}$ is in the order of $10^{-2} \mathrm{~S} / \mathrm{cm}$ (Koppalkar et al 2009). PANI doped with $\mathrm{ZrO}_{2}$ has shown higher thermal stability because of interaction between PANI and $\mathrm{ZrO}_{2}$, which is reported to resist the thermal motion of PANI chains and shields the degradation of PANI in the composites. PANI composites of $\mathrm{TiO}_{2}$ are proved to act as cathode material in rechargeable batteries. Similarly, PANI composite with $\mathrm{Mn}_{3} \mathrm{O}_{4}$ have been reported to behave as an NTC material (Majid et al 2007). PANI composite with $\mathrm{WO}_{3}$ has shown sensing properties (Narsimha et al 2006). The composites of PANI with other oxides, inorganic and organic substances like iron oxides, $\mathrm{MoS}_{2}, \mathrm{MnO}_{2}$, graphite and platinum have also been reported (Aphesteguy and Jacobo 2004). Therefore, literature shows that the chemical modification of PANI with suitable chemical species, induces varied dimensions in the composite material and desired characteristics can therefore be achieved by suitable chemical synthesis and modifications. Moving on the path of composite materials, insertion of inorganic complexes into the PANI backbone have led to the development of another category of conducting polymers known as hybrid materials, which are the current inquisition among material scientists. These hybrid systems possess varied properties and find applications in various fields like catalysis, sensors, bio-medical field (Greene et al 1975) and in corrosion study. Ethanolamines commonly known as aminoalcohols include mono-, di- and triethanolamines. Because of their basic nitrogen atom and hydroxyl group, the chemical properties resemble those of both amines and alcohols. The bifunctional nature of ethanolamines enables them to serve a variety of commercial applications such as inhibitors, surfactants, gas purification and herbicides (Esker et al 1999). The complexation of amino alcohols with transition metals have a long and varied history. Amino alcohols form complexes with transition metals like $\mathrm{Co}, \mathrm{Cu}, \mathrm{Cd}, \mathrm{Ni}, \mathrm{Zn}$, etc. These complexes show high thermal stability, lubricating properties and corrosion resistant properties. These complexes can prove as successful dopants for increasing the characteristic properties of conducting polymers. Keeping the lubricating, corrosion resistant properties and high thermal stability of complexes of cobalt with monoethanolamine in consideration, we here, report the synthesis and characterization of PANI and its composite with cobaltmonoethanolamine complex. The synthesized material has been subjected to various spectroscopic characterizations. Thermal and electrical properties of the synthesized material is also reported.

\section{Experimental}

\subsection{Materials and physical measurements}

Aniline was obtained by Loba Chemicals and was used after distillation. $\mathrm{HCl}$, ammonium peroxidisulphate, cobalt chloride and monoethanolamine were also provided by Loba Chemicals. $N$-methylpyrollidone was provided by Merck. All other reagents used were of analytical grade. UV-Visible spectra were taken on Shimadzu UV-190 double-beam spectrophotometer. Fourier transform infrared (FT-IR) spectra were recorded on Perkin Elmer RX-1 FT-IR spectrophotometer. The spectra were taken in $\mathrm{KBr}$ disks. Surface morphology of the samples was studied on a Hitachi SEM model S-3600N. X-ray diffraction (XRD) was recorded on PW 3050 base diffractometer with CuK $\alpha$ radiations $(1.54060 \AA)$. Thermogravimetric analysis coupled with DSC was carried out with universal TA instruments $\mathrm{V} 4.5 \mathrm{~A}$ in an argon atmosphere at a heating rate of $10{ }^{\circ} \mathrm{C} \mathrm{min}{ }^{-1}$. The temperature range was from ambient to $800^{\circ} \mathrm{C}$. An aluminium pan was used as a reference. The DSC was calibrated by the fusion of indium (99.99\% purity). Temperature repeatability of TA is $\pm 0.1^{\circ} \mathrm{C}$ and $\Delta H$ is $\pm 0.02 \mathrm{~mW}$. The experimental procedure involves placing of $15.33 \mathrm{mg}$ of sample in a pan, setting the pressure and heating rate. In this procedure, material was subjected to a linear temperature programme and the rate of heat flow into the material was continuously measured with increase in temperature. The temperature difference as a function of time shows peaks as heat is either absorbed or released by the sample under examination. $I-V$ characterization was done by Keithley electrometer/high resistance meter $6517 \mathrm{~A}$. The polymer composite was grinded by a mortar and pestle to obtain a fine powder form. The pellets of thickness $1 \mathrm{~mm}$ and diameter $12 \mathrm{~mm}$ were prepared from this powder material by applying a pressure of 5 ton. $I-V$ characteristics of the polymer composites were investigated at room temperature.

\subsection{Synthesis of PANI}

PANI was prepared by known methods of oxidation with ammonium persulphate $\left(\mathrm{NH}_{4}\right)_{2} \mathrm{~S}_{2} \mathrm{O}_{8}$. To pre-cooled solution of $10 \mathrm{~mL}$ distilled aniline dissolved in $150 \mathrm{~mL}$ of distilled water with $10 \mathrm{~mL}$ of concentrated $\mathrm{HCl}$ and $4.5 \mathrm{~g}$ of $\left(\mathrm{NH}_{4}\right)_{2} \mathrm{~S}_{2} \mathrm{O}_{8}$ dissolved in $30 \mathrm{~mL}$ of water was added drop-wise to the solution with constant stirring. Temperature was maintained at $0-5{ }^{\circ} \mathrm{C}$. The solutions were kept stirring for about $2 \mathrm{~h}$ and were left for more than $1 \mathrm{~h}$. The precipitate resulting from this solution was filtered and washed repeatedly in Buckner funnel under vacuum with distilled water. The precipitate was collected and dried in an oven at about $40{ }^{\circ} \mathrm{C}$.

\subsection{Synthesis of $\left[\mathrm{Co}(\text { mea })_{2}\left(\mathrm{H}_{2} \mathrm{O}\right)_{2} \mathrm{Cl}_{2}\right]$ complex}

The cobalt monoethanolamine $\left[\mathrm{Co}(\mathrm{mea})_{2}\left(\mathrm{H}_{2} \mathrm{O}\right)_{2} \mathrm{Cl}_{2}\right]$ complex was prepared by mixing $50 \mathrm{~mL}$ of $1 \mathrm{M}$ solution of monoethanolamine to $50 \mathrm{~mL}$ of $1 \mathrm{M}$ cobalt chloride solution. A pale violet precipitate resulting from this 
reaction upon refluxing is filtered and repeatedly washed with distilled water.

\subsection{Synthesis of PANI/[Co(mea $\left.)_{2}\left(\mathrm{H}_{2} \mathrm{O}\right)_{2} \mathrm{Cl}_{2}\right]$ composite}

The polyaniline composite was synthesized by in situ polymerization procedure. A typical preparation process for PANI composite is as follows: $10 \mathrm{~mL}$ distilled aniline and $10 \mathrm{~mL} \mathrm{HCl}$ were added to $100 \mathrm{~mL}$ distilled water and the mixture was allowed to pre-cool. A calculated amount of $\left[\mathrm{Co}(\mathrm{mea})_{2}\left(\mathrm{H}_{2} \mathrm{O}\right)_{2} \mathrm{Cl}_{2}\right]$ complex and ammonium persulphate was slowly added to the pre-cooled mixture upon constant stirring for about $3 \mathrm{~h}$ at a temperature maintained between $0-5{ }^{\circ} \mathrm{C}$. The mixture was allowed to react for $24 \mathrm{~h}$. A dark green precipitate obtained from the above reaction was washed repeatedly in the filtering funnel with distilled water. The precipitate was then dried in an oven at $40^{\circ} \mathrm{C}$ for $24 \mathrm{~h}$.

\subsection{Material preparation for corrosion study}

The material used for corrosion study is mild steel obtained from the mechanical workshop of the institute. The mild steel sheet of $1 \mathrm{~mm}$ thickness was mechanically press-cut into $5 \times 5 \mathrm{~cm}$ coupons. Mild steel was found to corrode in higher concentrations of $\mathrm{HNO}_{3}$. It was attributed to the fact that the rate of a chemical reaction increases with increase in concentration (Ita and Offiong 1997; Onuchukwu and Trasatti 1994). The test solution prepared was $3 \mathrm{M}$ nitric acid solution using standard procedure in $10 \%$ brine solution maintained at $\mathrm{pH} 2$. An excess amounts of $N$-methyl-pyrollidone was added to calculate the amount of polyaniline and polyaniline cobaltmonoethanolamine complex composite separately, so as to make the slurry of these materials for coating on coupons separately. The coatings on the coupons were obtained by dip-coating method, which involves dipping the coupons in the slurry for a period of $1 \mathrm{~h}$ followed by air drying. The thickness of films was in the range of 0.8 $0.97 \mathrm{~mm}$. All reagents were of AR grade and distilled water was used for the preparation of all solutions.

\subsection{Corrosion growth and weight loss measurements}

Previously weighed coupons of mild steel were immersed in beakers containing $10 \mathrm{~mL}$ of test solution maintained at room temperature. The coupons were retrieved at $24 \mathrm{~h}$ intervals progressively for $168 \mathrm{~h}$ (7 days). The difference in weight was noted as the weight loss in grams. The corrosion attack in nitric acid is very significant because nitric acid is known to be a strong oxidizing agent. The corrosion of mild steel sample in $\mathrm{HNO}_{3}$ solution is attributed to the presence of water, air and $\mathrm{H}^{+}$, which accelerates the corrosion process. The primary displacement of
$\mathrm{H}^{+}$ions from the solutions is followed by $\mathrm{HNO}_{3}$ reduction rather than hydrogen evolution, since the acid reduction leads to a marked decrease in free energy. The reaction can be summarized as follows

$$
\mathrm{Fe}+4 \mathrm{HNO}_{3} \rightarrow \mathrm{Fe}\left(\mathrm{NO}_{3}\right)_{2}+2 \mathrm{H}_{2} \mathrm{O}+2 \mathrm{NO}_{2} .
$$

This reaction leads to the evolution of nitrogen (II) oxide and production of $\mathrm{Fe}\left(\mathrm{NO}_{3}\right)_{2}$, which led to further colouration of the medium. The SEM of the sample on which corrosion was grown was taken before and after coating with PANI and its composite.

\section{Results and discussion}

\subsection{Elemental analysis}

The complex formed was analysed for $\mathrm{C}, \mathrm{H}$ and $\mathrm{N}$ and the empirical formula for the complex was found to be $\left[\mathrm{Co}(\mathrm{mea})_{2}\left(\mathrm{H}_{2} \mathrm{O}\right)_{2} \mathrm{Cl}_{2}\right]$. The observed percentages of $\mathrm{C}, \mathrm{H}$ and $\mathrm{N}$ are $10.67,4.90$ and $6.20 \%$, respectively, against the calculated percentages of $\mathrm{C}=10 \cdot 57, \mathrm{H}=4.85$ and $\mathrm{N}=6 \cdot 16 \%$.

\subsection{Optical absorption studies}

UV-Vis spectra of (a) pure PANI, PANI doped with (b) $20 \%$ [Co(mea $\left.)_{2}\left(\mathrm{H}_{2} \mathrm{O}\right)_{2} \mathrm{Cl}_{2}\right]$ complex, (c) $40 \%$ [Co(mea $)_{2}$ $\left.\left(\mathrm{H}_{2} \mathrm{O}\right)_{2} \mathrm{Cl}_{2}\right]$ complex, (d) $60 \%$ [Co(mea $\left.)_{2}\left(\mathrm{H}_{2} \mathrm{O}\right)_{2} \mathrm{Cl}_{2}\right]$ complex and (e) pure $\left[\mathrm{Co}(\mathrm{mea})_{2}\left(\mathrm{H}_{2} \mathrm{O}\right)_{2} \mathrm{Cl}_{2}\right]$ complex are shown in figure 1. The spectra of pure PANI (figure 1a) shows two distinct peaks at 291 and $352 \mathrm{~nm}$, which are attributed to the $\pi-\pi^{*}$ electron transition of the benzenoid

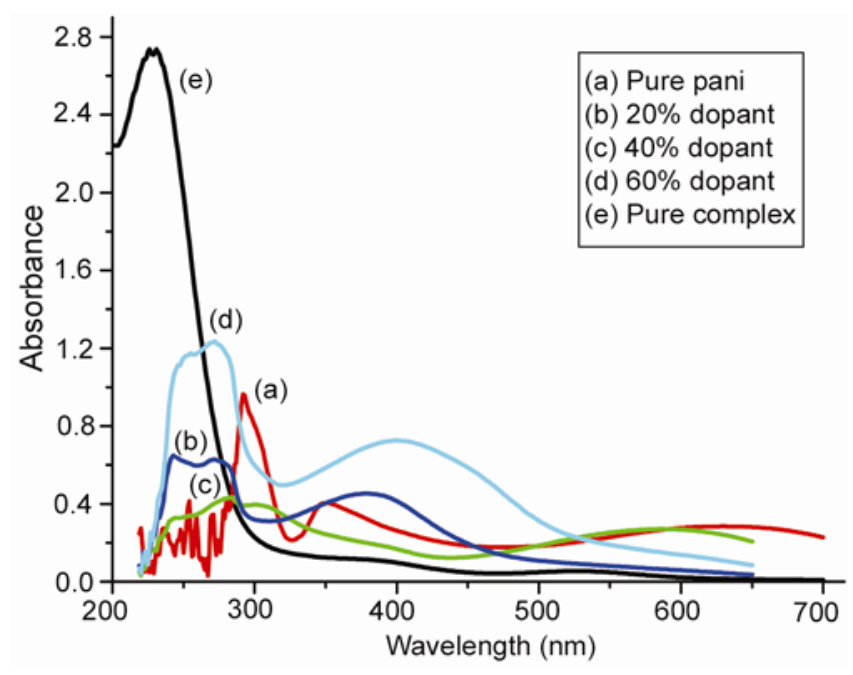

Figure 1. UV-Vis spectra of (a) pure PANI, (b) PANI doped with $20 \%$ [ $\left.\mathrm{Co}(\mathrm{mea})_{2}\left(\mathrm{H}_{2} \mathrm{O}\right)_{2} \mathrm{Cl}_{2}\right]$ complex, (c) PANI doped with $40 \%\left[\mathrm{Co}(\mathrm{mea})_{2}\left(\mathrm{H}_{2} \mathrm{O}\right)_{2} \mathrm{Cl}_{2}\right]$ complex, (d) PANI doped with $60 \%$ $\left[\mathrm{Co}(\mathrm{mea})_{2}\left(\mathrm{H}_{2} \mathrm{O}\right)_{2} \mathrm{Cl}_{2}\right]$ complex and (e) pure $\left[\mathrm{Co}(\text { mea })_{2}\left(\mathrm{H}_{2} \mathrm{O}\right)_{2} \mathrm{Cl}_{2}\right]$ complex. 
segment and polaron $-\pi^{*}$ transitions, respectively. A hump of $641 \mathrm{~nm}$ is observed, which is because of the $\pi-\pi^{*}$ electron transition of the quinoid segment. The transitions are matching with the reported results (Koul et al 2001). As the concentration of dopant is increased from 20 to $100 \%$, prominent and significant changes are observed. In a sample with $20 \%$ dopant concentration, the peaks due to the $\pi-\pi^{*}$ electron transition of the benzenoid segment and polaron $-\pi^{*}$ transitions seem to combine with each other. The peak at $291 \mathrm{~nm}$ is shifted to $334 \mathrm{~nm}$, which is in continuation with $352 \mathrm{~nm}$ peak. The hump observed at $641 \mathrm{~nm}$ is increasing its intensity and is reflected as a broad peak with a maximum at $638 \mathrm{~nm}$, which is due to $\pi-\pi^{*}$ transition of the quinoid segment. In sample with $40 \%$ dopant concentration peak due to $\pi-\pi^{*}$ transition of benzenoid segment is appearing separately at $292 \mathrm{~nm}$ with a slight shift and peak due to polaron $-\pi^{*}$ transition is appearing at $322 \mathrm{~nm}$ with a significant shift. Interestingly, the peak due to $\pi-\pi^{*}$ transition of quinoid segment is disappearing here. As dopant concentration is increased by another $20 \%$, i.e. sample with $60 \%$ dopant concentration, the peak due to $\pi-\pi^{*}$ transition of benzenoid segment is shifted to a higher wavelength side, i.e. $304 \mathrm{~nm}$ and peak due to polaron $-\pi^{*}$ is appearing at $321 \mathrm{~nm}$, while as peak due to $\pi-\pi^{*}$ transition of quinoid segment is missing here also. With $100 \%$ dopant concentration, i.e. in pure $\left[\mathrm{Co}(\text { mea })_{2}\left(\mathrm{H}_{2} \mathrm{O}\right)_{2} \mathrm{Cl}_{2}\right]$ complex, a single peak at $230 \mathrm{~nm}$ is observed, which can be attributed to MLCT transition. Therefore, on comparing the UV-Visible spectra of samples with varying concentration of dopant, interaction with the PANI and $\left[\mathrm{Co}(\text { mea })_{2}\left(\mathrm{H}_{2} \mathrm{O}\right)_{2} \mathrm{Cl}_{2}\right]$ complex is confirmed. Beyond 20\% dopant concentration, transition due to $\pi-\pi^{*}$ of the quinoid segment is lost. For effective conjugation and transition, $20 \%$ concentration of dopant proves to be a limiting concentration.

\subsection{FT-IR characterization}

FT-IR spectra of (a) PANI, (b) $\left[\mathrm{Co}(\text { mea })_{2}\left(\mathrm{H}_{2} \mathrm{O}\right)_{2} \mathrm{Cl}_{2}\right]$ complex and (c) $\mathrm{PANI} /\left[\mathrm{Co}(\text { mea })_{2}\left(\mathrm{H}_{2} \mathrm{O}\right)_{2} \mathrm{Cl}_{2}\right]$ composite are shown in figure 2. PANI shows a hump at $3305 \mathrm{~cm}^{-1}$ because of $\mathrm{N}-\mathrm{H}$ stretching. The strong peak at $2922 \mathrm{~cm}^{-1}$, because of $\mathrm{C}-\mathrm{H}$ stretching is observed. This absorption is also as a result of overtones or combination of some modes of benzene and quinoid units in PANI. A weak peak at $2852 \mathrm{~cm}^{-1}$ is observed because of $\mathrm{C}-\mathrm{H}$ stretching. The absorption peaks observed in the region of 1600 $1450 \mathrm{~cm}^{-1}$ are because of aromatic ring breathing, $\mathrm{N}-\mathrm{H}$ deformation and $\mathrm{C}-\mathrm{N}$ stretching. The peak at $1590 \mathrm{~cm}^{-1}$ is because of stretching of $\mathrm{N}=\mathrm{Q}=\mathrm{N}$ in PANI. A weak peak at $1377 \mathrm{~cm}^{-1}$ is also present in PANI. The peak at $1164 \mathrm{~cm}^{-1}$ in case of PANI can be because of a mode of $\mathrm{N}=\mathrm{Q}=\mathrm{N}$. The peak at $830 \mathrm{~cm}^{-1}$ in PANI is because of $\mathrm{C}-\mathrm{H}$ out of plane bending.

The complex formed is assigned molecular formula, $\left[\mathrm{Co}(\mathrm{mea})_{2}\left(\mathrm{H}_{2} \mathrm{O}\right)_{2} \mathrm{Cl}_{2}\right]$, on the basis of elemental analysis.
Further FT-IR shows the presence of different moieties as well. In case of this complex, we expect the vibrational frequencies due to ethanolamine, alcohol and amine group. Alcohol group involves $\mathrm{O}-\mathrm{H}$ stretch, which appears at $3349 \mathrm{~cm}^{-1}$ in alcohols. Moreover, we observe $\mathrm{C}-\mathrm{C}-\mathrm{O}$ symmetric stretch at about $817 \mathrm{~cm}^{-1}$ and $\mathrm{O}-\mathrm{H}$ in plane and out-of-plane bending vibrations at 1309 and $655 \mathrm{~cm}^{-1}$, respectively, since there is water present as a ligand in the complex which is clearly supported by FT-IR. Though, the appearance of $\mathrm{O}-\mathrm{H}$ stretch due to $\mathrm{H}_{2} \mathrm{O}$ at about $3446 \mathrm{~cm}^{-1}$ is similar in alcohols, but the presence of water is very clear from absorption peak at $1627 \mathrm{~cm}^{-1}$ due to scissoring of two $\mathrm{O}-\mathrm{H}$ bonds. This vibration is unique to water only, therefore, the presence of this band along with the $\mathrm{O}-\mathrm{H}$ stretch vibration at $3446 \mathrm{~cm}^{-1}$ is a very strong evidence of presence of water molecule as a ligand in the complex also. The presence of water molecules inside the coordination sphere as a ligand is confirmed from TG studies (figure 5b) also, where removal of two moles of water occur within the temperature of $20-275^{\circ} \mathrm{C}$. The observed and calculated weight loss corresponds to 15.96 and $15.86 \%$, respectively, therefore, clearly shows that water molecules are embedded inside the coordination sphere, thus, supports the elemental analysis results and empirical formula. The peaks at 1502, $1116,1064,731$ and $438 \mathrm{~cm}^{-1}$ are also observed in the complex, which can be because of $\delta-\mathrm{CH}_{2}, \rho-\mathrm{CH}_{2} . v-(\mathrm{C}-\mathrm{N})$, $v-\mathrm{C}-\mathrm{O}, \tau-\mathrm{CH}_{2}, v-(\mathrm{C}-\mathrm{C})$ and $v-(\mathrm{M}-\mathrm{N})$, respectively.

For successful synthesis of PANI composite with synthesized complex, we compare FT-IR of PANI

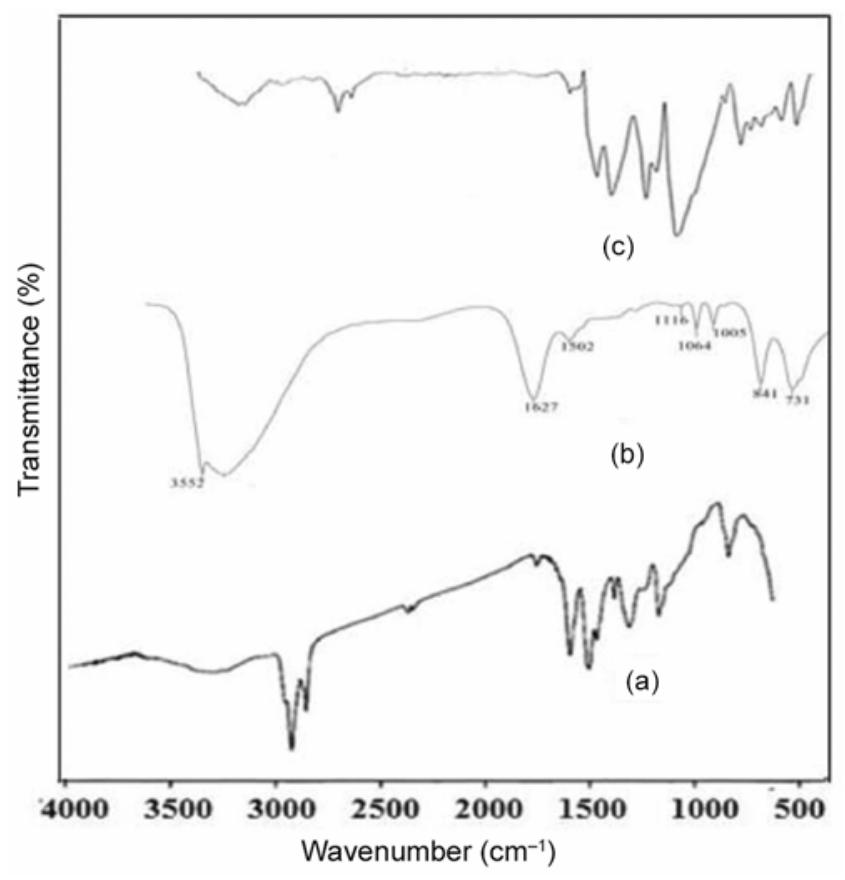

Figure 2. FT-IR of (a) PANI, (b) $\left[\mathrm{Co}(\text { mea })_{2}\left(\mathrm{H}_{2} \mathrm{O}\right)_{2} \mathrm{Cl}_{2}\right]$ complex and (c) composite of $\left[\mathrm{Co}(\mathrm{mea})_{2}\left(\mathrm{H}_{2} \mathrm{O}\right)_{2} \mathrm{Cl}_{2}\right]$ complex with PANI. 
(figure 2a), $\left[\mathrm{Co}(\text { mea })_{2}\left(\mathrm{H}_{2} \mathrm{O}\right)_{2} \mathrm{Cl}_{2}\right]$ complex (figure $2 \mathrm{~b}$ ) and PANI composite (figure 2(c)). PANI having a hump at $3305 \mathrm{~cm}^{-1}$ because of $\mathrm{N}-\mathrm{H}$ stretching shows a significant shift of $149 \mathrm{~cm}^{-1}$ and appears at $3447 \mathrm{~cm}^{-1}$ in the case of composite. The strong peak at $2922 \mathrm{~cm}^{-1}$, because of $\mathrm{C}-\mathrm{H}$ stretching remains unchanged. The presence of complex as the dopant in the composite is evident from the observation that in case of complex, we observe the absorption peak due to $v-(\mathrm{O}-\mathrm{H})$ of alcoholic group. This $v-(\mathrm{O}-\mathrm{H})$ is also because of presence of coordinated water, which is further confirmed by appearance of a peak at $1627 \mathrm{~cm}^{-1}$. This peak is also present in the case of composite with a less intensity and slight shifting at $1697 \mathrm{~cm}^{-1}$, therefore, proves the presence of complex as a dopant in PANI composite. The presence of dopant in the composite is also evident from the appearance of finger print region absorption peaks like $721 \mathrm{~cm}^{-1}$.

Therefore, from the discussion of FT-IR of pure PANI, $\left[\mathrm{Co}(\mathrm{mea})_{2}\left(\mathrm{H}_{2} \mathrm{O}\right)_{2} \mathrm{Cl}_{2}\right]$ complex and the composite of PANI with synthesized complex, the successful synthesis of composite of PANI with this complex is proved.

\section{$3.4 \quad X$-ray diffraction}

Figure 3 shows XRD pattern of PANI $\left[\mathrm{Co}(\mathrm{mea})_{2}\right.$ $\left.\left(\mathrm{H}_{2} \mathrm{O}\right)_{2} \mathrm{Cl}_{2}\right]$ complex and PANI/[Co(mea $\left.)_{2}\left(\mathrm{H}_{2} \mathrm{O}\right)_{2} \mathrm{Cl}_{2}\right]$ complex composite, respectively. From the XRD pattern of PANI (figure 3(a)), a hump is observed at around $20^{\circ}$. XRD pattern shows amorphous structure of the sample.

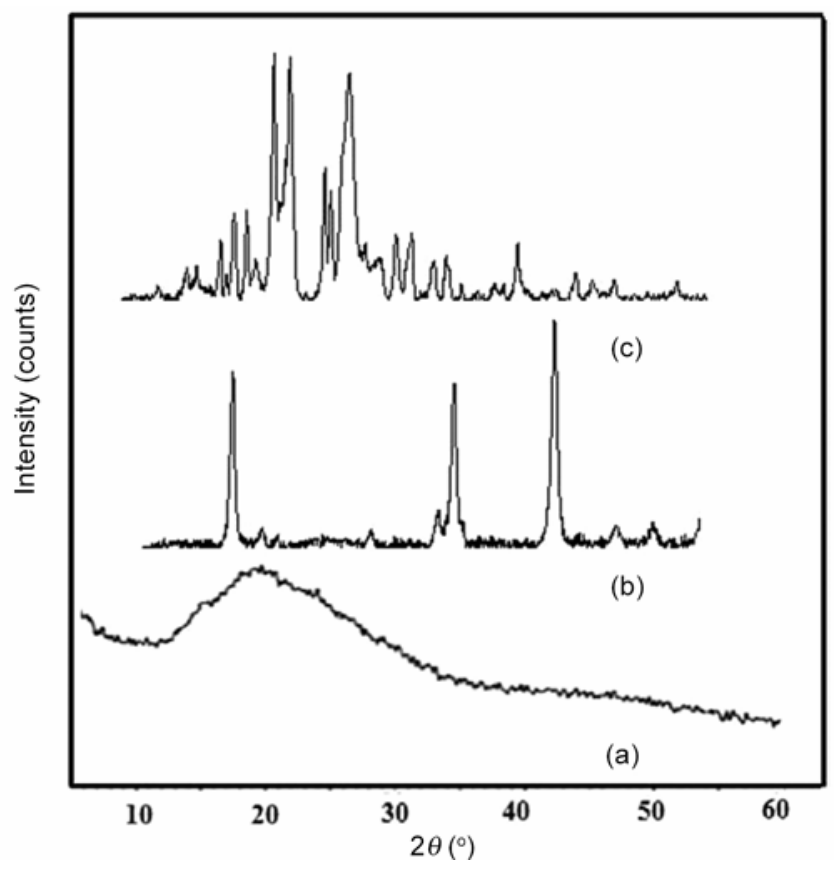

Figure 3. XRD spectra of (a) PANI, (b) $\left[\mathrm{Co}(\text { mea })_{2}\left(\mathrm{H}_{2} \mathrm{O}\right)_{2} \mathrm{Cl}_{2}\right]$ complex and (c) composite of $\left[\mathrm{Co}(\mathrm{mea})_{2}\left(\mathrm{H}_{2} \mathrm{O}\right)_{2} \mathrm{Cl}_{2}\right]$ complex with PANI.
XRD pattern of $\left[\mathrm{Co}(\text { mea })_{2}\left(\mathrm{H}_{2} \mathrm{O}\right)_{2} \mathrm{Cl}_{2}\right]$ complex (figure 3(b)) shows various sharp peaks with significant intensities showing compact structure, supporting the results from SEM. The observed data was fitted with Powder X software for structural analysis and the present complex shows monoclinic structure (space group $\mathrm{Pbca}$ ) with lattice parameters, $a=17.699 \AA, b=8.542 \AA$ and $c=28.12 \AA$ and corresponding Bragg's angles are $\alpha=\gamma=90^{\circ}$ and $\beta=93.96^{\circ}$. The various observed parameters (obtained from this analysis) for this system are summarized in table 1. The XRD pattern of PANI/[Co(mea $\left.)_{2}\left(\mathrm{H}_{2} \mathrm{O}\right)_{2} \mathrm{Cl}_{2}\right]$ complex composite also shows number of sharp and strong peaks at various $2 \theta$ values (figure $3 \mathrm{c}$ ). Composite has retained peaks of complex at slightly shifted positions. However, these peaks are of low intensity as observed in free complex form. XRD data of composite is verifying the successful synthesis of PANI composite with $\left[\mathrm{Co}(\mathrm{mea})_{2}\left(\mathrm{H}_{2} \mathrm{O}\right)_{2} \mathrm{Cl}_{2}\right]$ complex. The composite diffraction data was also analysed by using above software and best fit was obtained with orthorhombic structure (space group $P 2 / c$ ) with lattice parameters, $a=8.149 \AA$, $b=44.48 \AA$ and $c=25.82 \AA$ and corresponding Bragg's angles are $\alpha=\beta=\gamma=90^{\circ}$. Various parameters like interplanar distance $(d)$, peak intensities, peak area, etc. are also put in tabular form in table 2 .

It is quite indicative from the data that crystallinity of the PANI increases with $\left[\mathrm{Co}(\text { mea })_{2}\left(\mathrm{H}_{2} \mathrm{O}\right)_{2} \mathrm{Cl}_{2}\right]$ complex and make the PANI layers to be very close and consequently, the degree of crystallinity is increased. The increase in the crystalline nature causes an increase in the energy barriers to the segmental motion of the polymeric system. From composite, it is also evident that there are new diffraction peaks at about $2 \theta=15 \cdot 10,17 \cdot 61,20 \cdot 45$, $21.61,28.74,29.90$ and $36.94^{\circ}$, suggesting that the new phases possibility are formed due to the cross-linking of PANI with $\left[\mathrm{Co}(\mathrm{mea})_{2}\left(\mathrm{H}_{2} \mathrm{O}\right)_{2} \mathrm{Cl}_{2}\right]$ complex, which may be

Table 1. XRD data of $\left[\mathrm{Co}(\mathrm{mea})_{2}\left(\mathrm{H}_{2} \mathrm{O}\right)_{2} \mathrm{Cl}_{2}\right]$ complex.

\begin{tabular}{lrccc}
\hline $\operatorname{Pos} / 2 \theta\left(^{\circ}\right)$ & $d$-spacing $(\AA)$ & Height & Area & FMHW/2 $\theta\left(^{\circ}\right)$ \\
\hline 16.483 & 5.37368 & 34171.5 & 629519.5 & 0.3760 \\
31.258 & 2.85924 & 8273.3 & $199996 \cdot 1$ & 0.5151 \\
32.367 & 2.76373 & 31964.5 & $688348 \cdot 2$ & 0.4334 \\
39.566 & 2.27590 & 42407.3 & $962900 \cdot 6$ & 0.4729 \\
\hline
\end{tabular}

Table 2. XRD data of composite of polyaniline with $\left[\mathrm{Co}(\mathrm{mea})_{2}\left(\mathrm{H}_{2} \mathrm{O}\right)_{2} \mathrm{Cl}_{2}\right]$ complex.

\begin{tabular}{lrrcc}
\hline $\operatorname{Pos} / 2 \theta\left(^{\circ}\right)$ & $d$-spacing $(\AA)$ & Height & Area & FMHW $/ 2 \theta\left(^{\circ}\right)$ \\
\hline 20.431 & 4.34326 & $32380 \cdot 0$ & 534741.2 & $0 \cdot 3432$ \\
21.533 & 4.12348 & 32055.5 & $839530 \cdot 3$ & 0.5708 \\
23.877 & 3.72369 & 17241.7 & 196454.6 & $0 \cdot 2474$ \\
24.293 & 3.66097 & 14453.0 & $203591 \cdot 0$ & $0 \cdot 2887$ \\
25.537 & 3.48526 & 29814.8 & $1437125 \cdot 1$ & 0.9614 \\
\hline
\end{tabular}



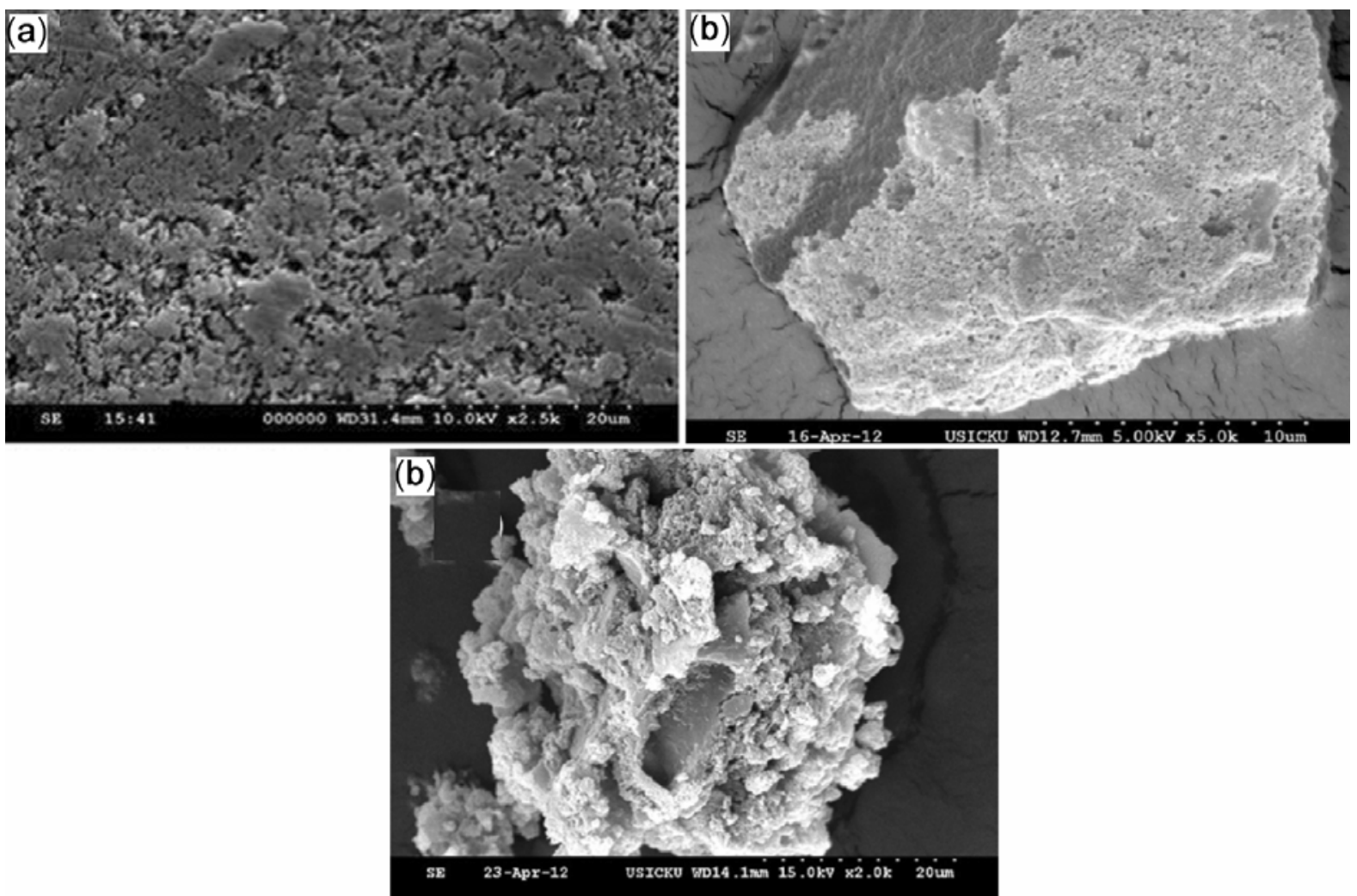

Figure 4. SEM micrographs of (a) pure PANI, (b) $\left[\mathrm{Co}(\mathrm{mea})_{2}\left(\mathrm{H}_{2} \mathrm{O}\right)_{2} \mathrm{Cl}_{2}\right]$ complex and (c) composite of $\left[\mathrm{Co}(\text { mea })_{2}\left(\mathrm{H}_{2} \mathrm{O}\right)_{2} \mathrm{Cl}_{2}\right]$ complex with PANI.

responsible for the formation of orthorhombic phase. Crystallite size $(G)$ of complex and its effect on the grain size of PANI composite was calculated using Scherer's formula

$$
G=k \lambda / \beta \cos \theta,
$$

where $K$ is Scherer's constant (its value is $0 \cdot 9$ ), $\lambda$ the wavelength of X-ray used (1.5406 $\AA$ ), $\theta$ the peak position measured in radian and $\beta$ the full width at half maximum (FWHM) (in radian 2 $\theta$ ) located at $2 \theta$. The calculated average crystallite size for complex and composite are about 51.466 and $52.323 \mathrm{~nm}$, respectively.

\subsection{Scanning electron microscope (SEM)}

Figure 4 shows SEM images of PANI (figure 4a), $\left[\mathrm{Co}(\mathrm{mea})_{2}\left(\mathrm{H}_{2} \mathrm{O}\right)_{2} \mathrm{Cl}_{2}\right]$ complex (figure $4 \mathrm{~b}$ ) and PANI/ $\left[\mathrm{Co}(\mathrm{mea})_{2}\left(\mathrm{H}_{2} \mathrm{O}\right)_{2} \mathrm{Cl}_{2}\right]$ complex composite (figure $4 \mathrm{c}$ ), respectively. Surface morphology of PANI sample shows amorphous structure. SEM of $\left[\mathrm{Co}(\mathrm{mea})_{2}\left(\mathrm{H}_{2} \mathrm{O}\right)_{2} \mathrm{Cl}_{2}\right]$ complex is showing a very compact morphology, which has dominated the surface morphology of PANI/[Co(mea $)_{2}$ $\left(\mathrm{H}_{2} \mathrm{O}\right)_{2} \mathrm{Cl}_{2}$ ] complex composite, clearly showing that the composite has been synthesized successfully. Further, SEM image of composite is showing improvement in compactness.

\subsection{Thermal analysis}

TG/DSC of PANI, [Co(mea $\left.)_{2}\left(\mathrm{H}_{2} \mathrm{O}\right)_{2} \mathrm{Cl}_{2}\right]$ complex, and composite of PANI with $\left[\mathrm{Co}(\mathrm{mea})_{2}\left(\mathrm{H}_{2} \mathrm{O}\right)_{2} \mathrm{Cl}_{2}\right]$ complex are shown in figure 5. TG of pure PANI (figure 5(a)) shows two transitions. The first transition starts from $18^{\circ} \mathrm{C}$ and ends at $85^{\circ} \mathrm{C}$ with an observed weight loss of $4.33 \%$, which shows that moisture is embedded in the outer layers of the material. The second transition starts from $278{ }^{\circ} \mathrm{C}$ and ends at $590{ }^{\circ} \mathrm{C}$, with a weight loss of $49.82 \%$, which is because of release of organic moieties like $\mathrm{C}, \mathrm{H}$ and $\mathrm{N}$. In DSC, two endothermic peaks are observed for pure PANI. One having a peak temperature of $70.7^{\circ} \mathrm{C}$ and the other with a peak temperature of $264 \cdot 3^{\circ} \mathrm{C}$

TG curve of $\left[\mathrm{Co}(\mathrm{mea})_{2}\left(\mathrm{H}_{2} \mathrm{O}\right)_{2} \mathrm{Cl}_{2}\right]$ complex (figure $5 \mathrm{~b}$ ) shows two transitions. The first transition starts from $20^{\circ} \mathrm{C}$ and ends at $275^{\circ} \mathrm{C}$, with an observed weight loss of $15.96 \%$, against calculated weight loss of $15.86 \%$ attributed to removal of two moles of $\mathrm{H}_{2} \mathrm{O}$. The second transition starts from $275.38^{\circ} \mathrm{C}$ and ends at $708.26^{\circ} \mathrm{C}$ with an observed weight loss of $27 \cdot 16 \%$, against a calculated weight loss of $26 \cdot 88 \%$ because of removal of 2 moles of $\mathrm{CH}_{2}$, one mole of $\mathrm{OH}$ and one mole of $\mathrm{NH}_{2}$. The residue left behind is $\mathrm{CoCl}_{2}$ at $708.26^{\circ} \mathrm{C}$, which shows stability up to $800^{\circ} \mathrm{C}$. The observed weight left is $56 \%$, against calculated percentage of $57 \cdot 24 \%$. 
DSC of $\left[\mathrm{Co}(\mathrm{mea})_{2}\left(\mathrm{H}_{2} \mathrm{O}\right)_{2} \mathrm{Cl}_{2}\right]$ complex also shows two transitions, out of which, one is endothermic starting from 20 to $100{ }^{\circ} \mathrm{C}$ with a maximum at $70^{\circ} \mathrm{C}$. The second transition is an exothermic transition which combines two transitions of $\mathrm{TG}$ curves, starts from $210^{\circ} \mathrm{C}$ and ends at $671{ }^{\circ} \mathrm{C}$ with a maximum at $434{ }^{\circ} \mathrm{C}$.

TG curve of the composite is shown in figure 5(c). The thermogram can be explained in two transitions. First transition starts from an ambient temperature and ends at $94.76{ }^{\circ} \mathrm{C}$ with a weight loss of $15 \cdot 19 \%$, which is due to
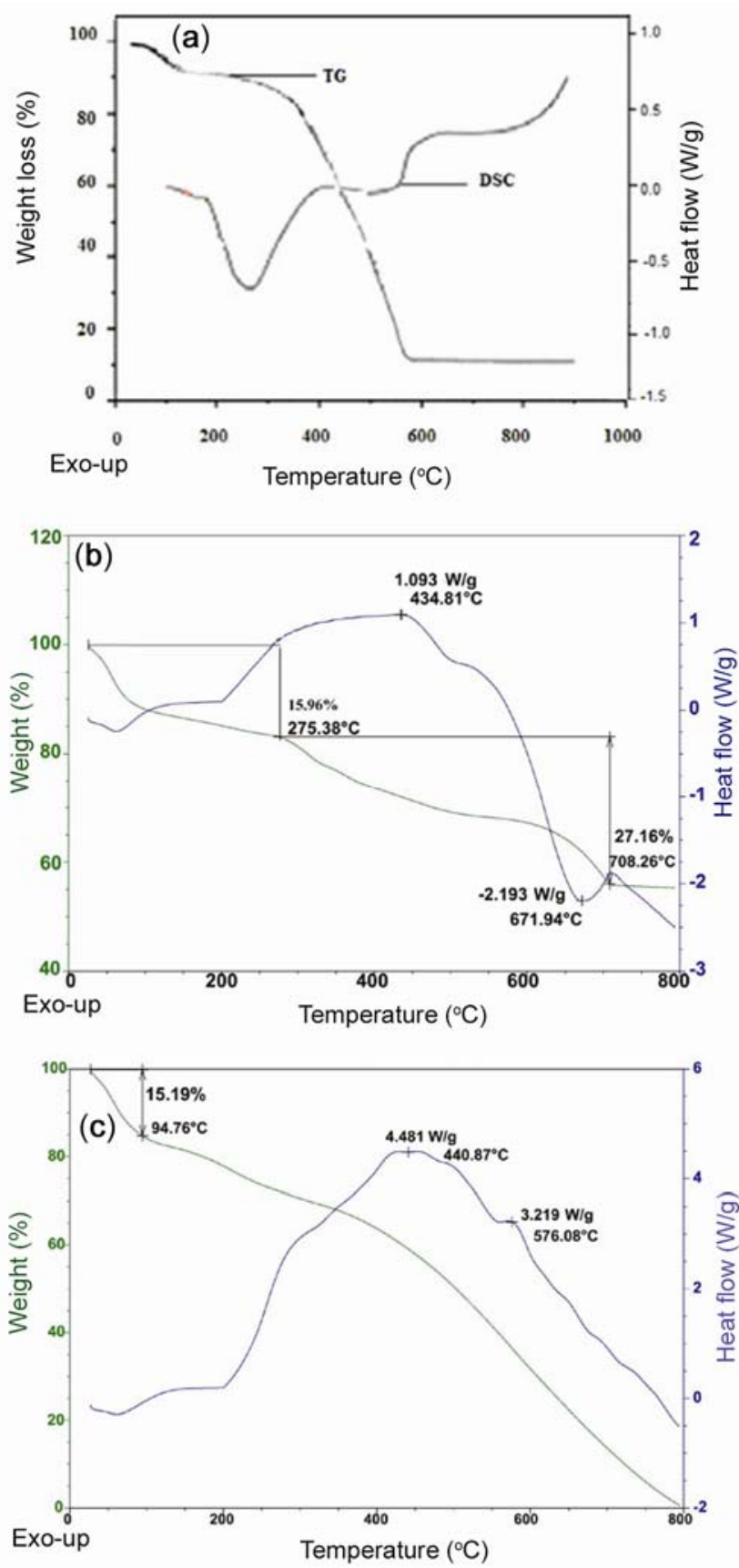

Figure 5. TG/DSC analysis of (a) PANI, (b) $\left[\mathrm{Co}(\mathrm{mea})_{2}\right.$ $\left.\left(\mathrm{H}_{2} \mathrm{O}\right)_{2} \mathrm{Cl}_{2}\right]$ complex and (c) composite of $\left[\mathrm{Co}(\mathrm{mea})_{2}\left(\mathrm{H}_{2} \mathrm{O}\right)_{2} \mathrm{Cl}_{2}\right]$ complex with PANI. loss of moisture embedded in the layers of composite material as final temperature is below $200{ }^{\circ} \mathrm{C}$. Whereas, in the composite, second degradation step has resulted into complete decomposition at $800{ }^{\circ} \mathrm{C}$ without any residue left implies that whole complex and PANI have resulted into the composite formation, however, thermal stability of the composite has increased.

On comparing TG of complex and composite, it is evident that in complex, the decomposition process ends at $700{ }^{\circ} \mathrm{C}$ with observed $56 \%$ residue against calculated weight of $57 \cdot 24 \%$. The presence of complex in the composite has resulted into enhanced thermal stability as the last transition of composite lasts up to $800{ }^{\circ} \mathrm{C}$ with complete decomposition.

\section{$3.7 \quad I-V$ characteristics}

$I-V$ characteristic as shown in figure 6 exhibits non-linear behaviour for pure PANI and composite of PANI with $20 \%$ dopant concentration. From the $I-V$ plot, it is evident that as the voltage increases, the change in value of current is significantly lower in pure PANI compared to composite with $20 \%$ dopant concentration. Also, it is evident from the graph that the curve corresponding to composite with $20 \%$ dopant concentration attains sharp sigmoidal shape showing semiconducting nature and hence, increase in current in the composite compared to pure PANI. In the present composite system, the polymerization of PANI with $\left[\mathrm{Co}(\text { mea })_{2}\left(\mathrm{H}_{2} \mathrm{O}\right)_{2} \mathrm{Cl}_{2}\right]$ complex causes strong interfacial interactions between PANI and $\left[\mathrm{Co}(\mathrm{mea})_{2}\left(\mathrm{H}_{2} \mathrm{O}\right)_{2} \mathrm{Cl}_{2}\right]$ complex crystallites, as suggested by FT-IR and XRD studies, thereby changing the molecular conformation of PANI from compact coil structure to an expanded coil-like structure. As a consequence, there is an enhancement in the current with voltage in the composite of PANI with $20 \%$ dopant concentration. As the concentration of dopant is increased to 40,60 and $100 \%$, the resistance increases to a large extent hence, showing insulating behaviour. The increase in current with voltage in composite with $20 \%$ dopant concentration only can also be attributed to the prominence

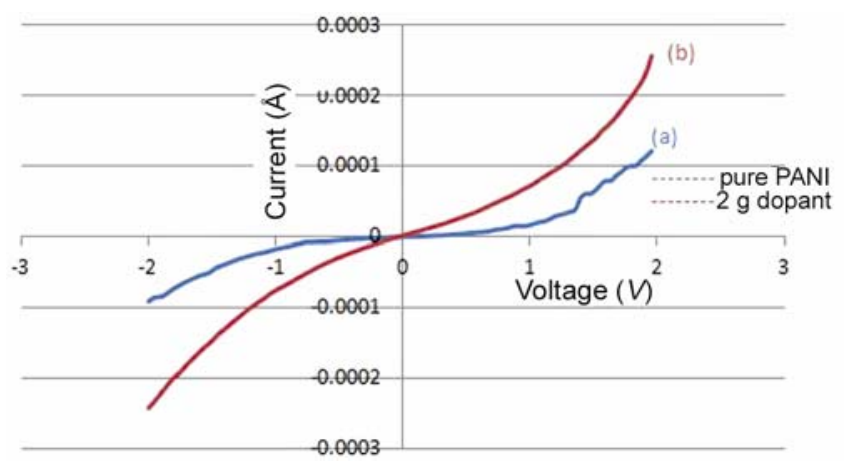

Figure 6. $I-V$ plot of (a) pure PANI and (b) composite with $20 \%$ dopant concentration. 

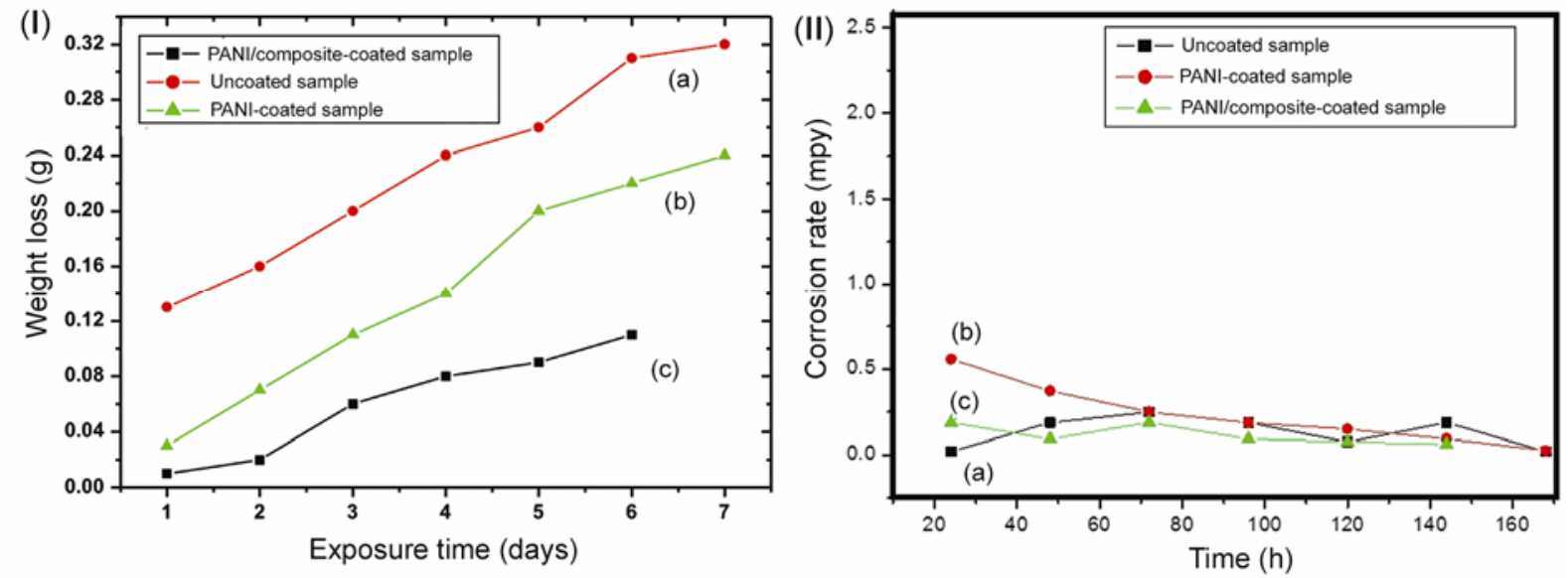

Figure 7. (I) Variation of weight loss (g) with time (days) for mild steel: (a) uncoated sample, (b) PANI-coated sample and (c) composite-coated sample. (II) Rate of corrosion with time (h) for mild steel: (a) uncoated sample, (b) PANI-coated sample and (c) composite-coated sample.
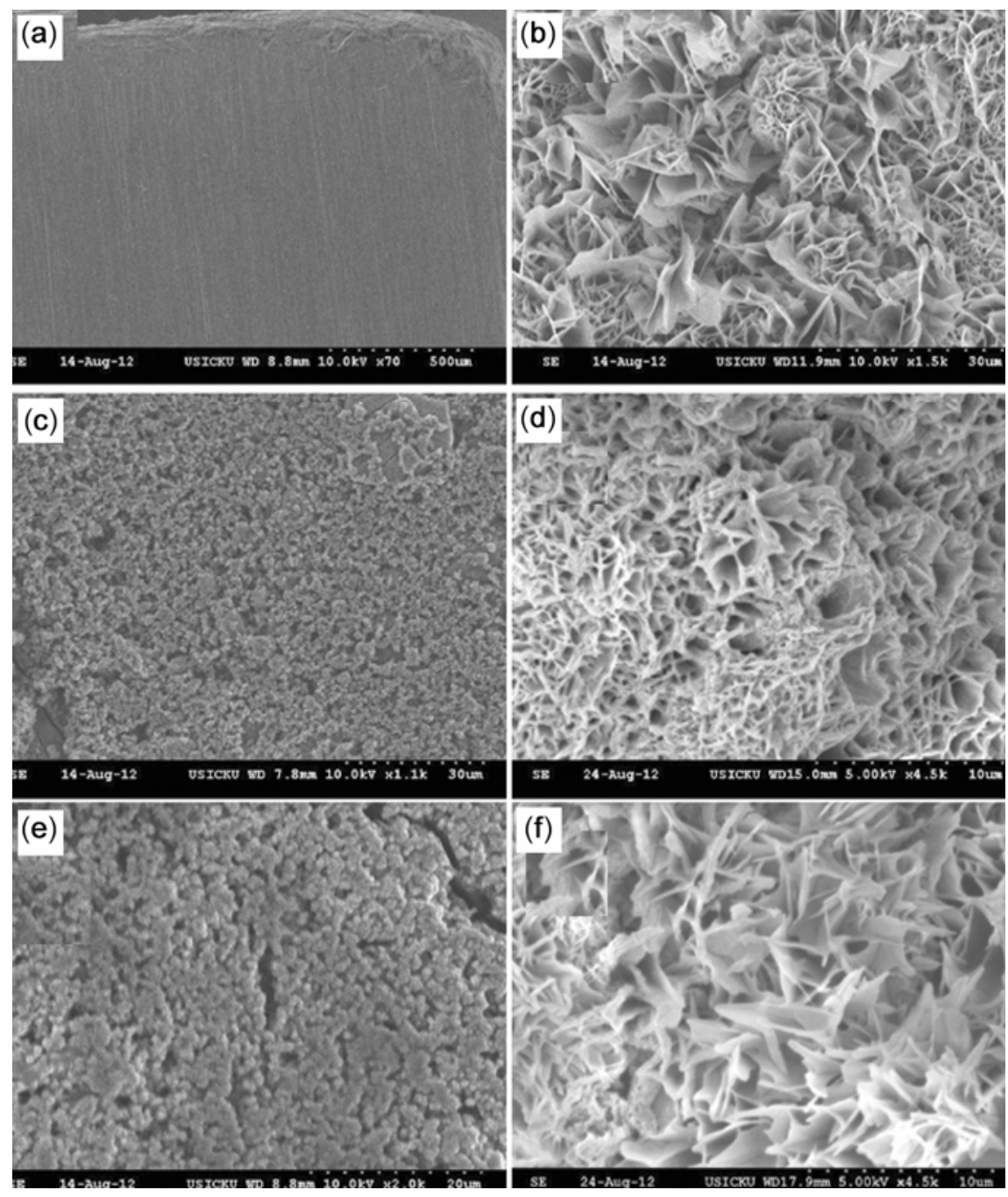

Figure 8. SEM micrographs obtained before and after corrosion in $3 \mathrm{M}$ nitric acid solution: (a) uncoated steel sample before corrosion, (b) uncoated steel sample after corrosion, (c) steel sample coated with PANI, (d) PANI-coated steel sample after corrosion, (e) composite-coated steel sample before corrosion and (f) composite-coated steel sample after corrosion. 
of $\pi-\pi^{*}$ transition of the quinoid segment in this composite as shown in figure 1(b). However, in case of composites with 40 and $60 \%$ dopant concentrations, the same peak disappears hence, increase in resistance takes place.

\subsection{Corrosion study}

A steel sample of composition, copper $0 \cdot 14 \%$, manganese 0.35 , silicon $0 \cdot 17$, sulphur 0.025 , phosphorus $0.03 \%$ and iron $99.285 \%$ was taken as a reference material, SEM image of which is shown in figure 8(a). The significant corrosion growth in $\mathrm{HNO}_{3}$ takes place at a concentration of $3 \mathrm{M}$ and $\mathrm{pH} 2$ for mild steel samples (Onuchukwu and Trasatti 1994; Ita and Offiong 1997) used as reference material as the conditions were optimized after carrying out experiments with different $\mathrm{HNO}_{3}$ concentrations. Therefore, the uncoated material, PANI-coated material and composite-coated materials were allowed to corrode in the prepared test solution of $\mathrm{HNO}_{3}$ and were analysed by the way of changes in weight and morphology. The weight loss measurement recorded as a function of time on different samples is shown in figure 7(I). It is clear from the figure that in uncoated steel sample, weight loss is maximum, whereas in case of PANI composite-coated steel sample, weight loss is minimum. This proves that the synthesised PANI composite acts as a corrosion inhibitor. The figure also reveals that the weight loss of steel samples increase with time. This observation is attributed to the fact that the rate of a chemical reaction increases as the exposure time is increased. In figure 7(II), corrosion rates of mild steel has been given. The corrosion rates of the samples were determined using the standard mathematical relation (Wranglen 1985; Fontana 1987; Vernon 1992).

\section{Corrosion rate $(\mathrm{mpy})=534 \mathrm{~W} / \rho \mathrm{AT}$,}

where $W$ is the weight loss in $\mathrm{mg}, \rho$ the density in $\mathrm{g} / \mathrm{cm}^{3}$, $A$ the total surface area in $\mathrm{cm}^{2}, T$ the exposure time in hours and mpy the mils per year. The measured density of material used is $78.7 \mathrm{~g} / \mathrm{cm}^{3}$. Figure 7 (II) shows that in uncoated steel sample, preferential corrosion is taking place in the early part. From the plot, it is also clear that the corrosion rates decrease with time, in case of PANI and PANI/composite-coated steel sample. However, the rate of corrosion in case of composite-coated sample is much less compared to that of PANI-coated steel sample. Thus, showing that PANI/composite coating is potent inhibitor for corrosion. This may be attributed to the fact that the composite film acts as a passive layer on the mild steel which prevents the mild steel from significant interaction with environment. As a result of growth of corrosion in steel samples, there would be significant change in surface morphology of the samples for which SEM images of uncoated, PANI-coated and PANI compositecoated samples before and after the growth of corrosion were taken. Figure $8(a-f)$, which shows that in case of
PANI-coated sample, the effect of corrosion is less than what is observed in uncoated mild steel surface. This prevention effect is looking more enhanced in case of samples coated with PANI composite material which proves that PANI/[Co(mea $\left.)_{2}\left(\mathrm{H}_{2} \mathrm{O}\right)_{2} \mathrm{Cl}_{2}\right]$ composite improved the corrosion resistance properties of PANI.

\section{Conclusions}

The preparation of $\mathrm{PANI} /\left[\mathrm{Co}(\mathrm{mea})_{2}\left(\mathrm{H}_{2} \mathrm{O}\right)_{2} \mathrm{Cl}_{2}\right]$ composite was successfully performed by in situ polymerization method and incorporation of $\left[\mathrm{Co}(\text { mea })_{2}\left(\mathrm{H}_{2} \mathrm{O}\right)_{2} \mathrm{Cl}_{2}\right]$ complex in the polyaniline matrix was confirmed by optical absorption study, FT-IR, SEM, TG/DSC and XRD studies. Thermal analysis shows enhanced thermal stability of polyaniline. The polymerization of PANI with $\left[\mathrm{Co}(\mathrm{mea})_{2}\right.$ $\left(\mathrm{H}_{2} \mathrm{O}\right)_{2} \mathrm{Cl}_{2}$ ] complex causes strong interfacial interactions between PANI and $\left[\mathrm{Co}(\text { mea })_{2}\left(\mathrm{H}_{2} \mathrm{O}\right)_{2} \mathrm{Cl}_{2}\right]$ complex crystallites, also suggested by FT-IR and XRD studies, thereby changing the molecular conformation of PANI from compact-coil structure to an expanded-coil like structure. As a consequence, there is an enhancement in the conductivity of composite of PANI up to $20 \%$ dopant concentration. Results of the corrosion study showed that in $3 \mathrm{M}$ $\mathrm{HNO}_{3}$ solution, the effect of corrosion on mild steel coated with $\mathrm{PANI} /\left[\mathrm{Co}(\text { mea })_{2}\left(\mathrm{H}_{2} \mathrm{O}\right)_{2} \mathrm{Cl}_{2}\right]$ composite is much lower than that on mild steel-coated with pure polyaniline.

\section{Acknowledgements}

The authors are grateful to Prof. Rajat Gupta, Director, NIT, Srinagar and Dr S A Shah, Head, Department of Chemistry, NIT, Srinagar, for help and support.

\section{References}

Aphesteguy, J C and Jacobo S E 2004 Physica B 354224

Esker T, Deboo A and Ishiwa Y 1999 Ethanolamines, Chemical Economics Handbook (CEH) Report

Fontana M G 1987 Corrosion Eng. 3rd edn (Singapore: McGraw-Hill Book Co.)

Gurunathan K, Amalnerkar D P and Trivedi D C 2003 Mater. Lett. 571648

Greene R L, Street G B and Sutude L J 1975 Phys. Rev. Lett. 34 577

Ita B I and Offiong O E 1997 Mater. Chem. Phys. 51203

Kaeami H, Mousavi M F and Shamsipur M 2003 Pow. Sou. 117 255

Koppalkar R A, Ameena P, Badiger G R and Ambika M V N 2009 Physica B 4041664

Koul S, Dhawan S K and Chandra R 2001 Synth. Met. 124295

Kros A, Van H S W, Nolte R J M and Sommerdijk N A 2001 Sensor Actuator $\mathbf{8 0} 229$

Lee C Y, Kim H M, Park J W, Gal Y S, Jin J I and Joo J 2001 Synth. Met. 117109

Lin C W, Hwang B J and Lee C R 1998 Mater. Chem. Phys. 55 139 
Majid K, Awasthi S and Singla M L 2007 Sensor Actuator A135 113

Meixiang W 1998 Synth. Met. 92121

Narsimha P, Shilpa J, Syed Khasim M, Revansiddappa S V, Bhoraskar M V N and Ambika P 2006 Sensor Actuator B114 599

Noh K A, Kim D W, Jin C S, Shin K H, Kim J H and Ko J M 2003 Pow. Sou. 124595

Onuchukwu A I and Trasatti S P 1994 Corr. Sci. 361815

Osarolube E, Owate I O and Oforka N 2008 Sci. Res. Essay 3224

Pfaendner R 2010 Polymer Degrad. Stabil. 95369
Sambhu B, Nikhil K S and Dipak K 2011 Chem. Eng. Mater. Sci. 21

Skotheim T A, Elsenbaumer R L and Reynolds J 1998 (New York: Marcel Dekker)

Vernon 1992 Sci. Res. Essay 3224

Wranglen 1985 Sci. Res. Essay 3224

Yamauchi T, Tansuriyavong S, Doi K, Oshima K, Shimomura M, Tsubokawa N, Miyauchi S and Vincent J V F 2005 Synth. Met. 15245

Zarras P, Stenge S J D and Wei 2003 ACS Symp. Series (Washington) 